\title{
The Impact of Paliperidone Palmitate on Hospitalization in Patients with Schizophrenia: A Retrospective Mirror-image Study
}

\author{
So-Young $\mathrm{Oh}^{1}$, Duk-In Jon ${ }^{1}$, Hyun Ju Hong ${ }^{1}$, Narei Hong ${ }^{1}$, Jung-Seo $\mathrm{Yi}^{2}$, Daeyoung Roh $^{3}$, Myung Hun Jung ${ }^{1}$ \\ ${ }^{1}$ Department of Psychiatry, Hallym University Sacred Heart Hospital, Hallym University College of Medicine, Anyang, ${ }^{2}$ Department of Psychiatry, \\ Hallym University Kangnam Sacred Heart Hospital, Hallym University College of Medicine, Seoul, ${ }^{3}$ Mind-neuromodulation Laboratory and \\ Department of Psychiatry, Chuncheon Sacred Heart Hospital, Hallym University College of Medicine, Chuncheon, Korea
}

\begin{abstract}
Objective: Whether long-acting injectable antipsychotics (LAI) are superior to oral antipsychotics remains a controversial question, and results vary depending on the study design. Our study was performed to compare outcomes of oral antipsychotics and paliperidone palmitate (PP) in clinical practice by investigating the numbers of admissions and bed days. Methods: We performed a retrospective observational mirror-image study at a single medical center, reviewing medical charts to obtain the clinical data. Forty-six patients with a diagnosis of schizophrenia or schizoaffective disorder who had received at least two doses of PP were included in the analysis. The Wilcoxon signed-rank test was used to compare the numbers of bed days and admissions 1 year before starting PP with those numbers at 1 year after.

Results: The mean number of admissions fell from 0.83 to 0.17 per patient $(p<0.0002)$, and the median fell from 1 to 0 . The mean number of bed days decreased significantly, from 24.85 to 8.74 days $(p<0.006$ ). The outcomes remained similar in sensitivity analyses set up with different mirror points.

Conclusion: Our results indicate that initiating PP reduced the mean numbers of hospital admissions and bed days compared with prior oral medication. LAls may thus be cost effective in practice; its use bringing about cost reductions greater than its purchase cost.
\end{abstract}

KEY WORDS: Schizophrenia; Paliperidone palmitate; Mirror-image study; Number of admissions; Number of bed days; Sensitivity analyses.

\section{INTRODUCTION}

Schizophrenia is a chronic mental disorder that often requires a long period of antipsychotic treatment to reduce symptom distress and risk of relapse [1,2]. However, nonadherence to antipsychotic medication is common in patients with schizophrenia, and it is one of the largest problems making treatment difficult $[3,4]$. Many approaches have been adopted to improve adherence, such as various psychosocial interventions, motivational interviewing, electronic reminders, and financial incentives [5]. Among these interventions, long-acting injectable antipsychotics

Received: May 7, 2019/ Revised: June 18, 2019

Accepted: June 19, 2019

Address for correspondence: Myung Hun Jung

Department of Psychiatry, Hallym University Sacred Heart

Hospital, 22 Gwanpyeong-ro 170beon-gil, Dongan-gu, Anyang

14068, Korea

E-mail: mhjung@hallym.or.kr

ORCID: https://orcid.org/0000-0003-2393-3930
(LAIs) are a potential strategy to manage nonadherence $[6,7]$. LAls are a potent tool because a steady plasma drug concentration can be maintained if medication is administered properly [8], and physicians can recognize patients' noncompliance immediately. Furthermore, the plasma drug concentration does not drop immediately, even if the patient skips the injection for a few days, and there is no need to remember to take pills daily [9].

Paliperidone is 9-hydroxy metabolite of risperidone, a selective dopamine $\left(\mathrm{D}_{2}\right)$ and serotonin $\left(5-\mathrm{HT}_{2 \mathrm{~A}}\right)$ antagonist [10]. Paliperidone palmitate (PP) is a long-acting injectable formulation of the paliperidone palmitoyl ester that was introduced to South Korea commercially in 2012. PP use is relatively easy because the long half-life of PP allows for a once-monthly injection, and supplementation with oral antipsychotics is not necessary, unlike other LAIs [11]. In addition, PP has proven effective not only in preventing relapse during maintenance treatment but also in

(ㄷ) This is an Open-Access article distributed under the terms of the Creative Commons Attribution Non-Commercial License (http://creativecommons.org/licenses/by-nc/4.0) which permits unrestricted non-commercial use, distribution, and reproduction in any medium, provided the original work is properly cited. 
reducing symptoms during acute treatment [12-15].

However, whether LAls, including PP, demonstrate efficacy superior to that of oral antipsychotics in patients with schizophrenia remains controversial. Most observational studies, including cohort and mirror-image studies, have reported greater effectiveness for LAIs [16]. In contrast, randomized controlled trials (RCTs) generally show equivalence for the two treatments in preventing relapse, reducing psychotic symptoms, and all-cause discontinuation [17]. RCTs tend to recruit patients who are relatively adherent to medication, present less severe symptoms, and have better cognitive abilities. They are hardly representative of LAI-treated patients in clinical practice; thus, they could not reap the benefits of LAI treatment, such as better compliance $[18,19]$. Methodological studies are needed to compare the efficacy of oral antipsychotics and LAls.

The current study evaluated whether PP has an effect on acute inpatient hospitalization rates by conducting a retrospective observational 1 -year mirror-image study at a single medical center in South Korea.

\section{METHODS}

\section{Subjects}

Patients with the Diagnostic and Statistical Manual of Mental Disorders, 5th edition (DSM-5) schizophrenia or schizoaffective disorder [20], and aged 18-65 years were included if they had received two loading doses of PP and had a prescription for an oral antipsychotic 1 year before initiating PP. They were excluded if complete data were not available for any reason, such as hospital transfer or loss to follow-up. Of 89 patients recruited from a single medical center (three university hospitals), 46 met the criteria and were included in the analysis.

\section{Data Collection}

The present study was a retrospective mirror-image study that screened electronic patient records between September 2013 and December 2017. We collected data on the number of admissions and the number of bed days for 1 year before and 1 year after initiating PP. Details, including age at initiation of PP, sex, education level, illness duration, Clinical Global Impression-Severity scale (CGI-S) [21] score obtained at initiation of PP, and previous oral antipsychotics used and dose were recorded. The pre- vious oral antipsychotic dose was converted to chlorpromazine (CP) equivalent doses for a quantitative comparison [22]. This study was conducted after obtaining approval from the Institutional Review Board (IRB no. HALLYM 2019-02-007).

\section{Statistical Analysis}

All statistical analyses were performed using SPSS version 24.0 for Windows software (IBM Co., Armonk, NY, USA). Baseline characteristics were summarized using descriptive statistics. Means and standard deviations (SDs) were calculated for continuous data, and frequencies and percentages were determined for categorical data. The distributions of the number of admissions and the number of bed days were not normal, as confirmed by the Kolmogorov-Smirnov test and Shapiro-Wilk tests. Therefore, these analyses were conducted using the

Table 1. Demographic and clinical characteristics of patients who had received PP

\begin{tabular}{|c|c|}
\hline Parameter at initiation of PP & Value $(n=46)$ \\
\hline \multicolumn{2}{|l|}{ Age (yr) } \\
\hline Mean \pm standard deviation & $46.3 \pm 12.1$ \\
\hline Range & $18-65$ \\
\hline \multicolumn{2}{|l|}{ Sex } \\
\hline Male & $21(45.7)$ \\
\hline Female & $25(54.3)$ \\
\hline \multicolumn{2}{|l|}{ Level of education } \\
\hline$\leq 6 \mathrm{yr}$ & $4(8.7)$ \\
\hline$\leq 9 \mathrm{yr}$ & $1(2.2)$ \\
\hline$\leq 12 \mathrm{yr}$ & $22(47.8)$ \\
\hline$>12 \mathrm{yr}$ & $19(41.3)$ \\
\hline \multicolumn{2}{|l|}{ Diagnosis } \\
\hline Schizophrenia & $43(93.5)$ \\
\hline Schizoaffective disorder & $3(6.5)$ \\
\hline \multicolumn{2}{|l|}{ Years of psychiatric illness } \\
\hline Mean \pm standard deviation & $13.8 \pm 8.9$ \\
\hline \multicolumn{2}{|l|}{ Care setting } \\
\hline Inpatient & $17(37.0)$ \\
\hline Outpatient & $29(63.0)$ \\
\hline \multicolumn{2}{|l|}{ CGI-S } \\
\hline 3 (Mildly ill) & $6(13.0)$ \\
\hline 4 (Moderately ill) & $14(30.4)$ \\
\hline 5 (Markedly ill) & $17(37.0)$ \\
\hline 6 (Severely ill) & $9(19.6)$ \\
\hline \multicolumn{2}{|c|}{$\mathrm{CP}$ equivalent dose of previous oral antipsychotics } \\
\hline $0-399 \mathrm{mg} /$ day & $22(47.8)$ \\
\hline $400-799 \mathrm{mg} / \mathrm{day}$ & $13(28.3)$ \\
\hline$\geq 800 \mathrm{mg} /$ day & $11(23.9)$ \\
\hline
\end{tabular}

Values are presented as number (\%).

$\mathrm{PP}$, paliperidone palmitate; CGI-S, the clinical global impressionseverity scale; $C P$, chlorpromazine. 
Wilcoxon signed-rank test. If PP was initiated in an outpatient setting, the mirror date was set as the day PP was initiated. If PP was initiated during hospitalization, that index admission was considered a failure of previous treatment. As PP needs 1 week to achieve a steady-state plasma concentration [23], the mirror date was set as 8 days after initiating PP. A $p$ value $<0.05$ was considered significant.

\section{RESULTS}

\section{Patient Characteristics}

Data were collected for 89 consecutive patients who were prescribed PP. After applying the inclusion criteria, 46 patients remained for analysis. Patients' demographic details are given in Table 1. Patients were excluded because of incomplete medical records 1 year before starting the injections, follow-up loss or transfer within less than 1 year after starting the injections, and refusal to take a second loading dose because of pain or other reasons. The mean age of the participants was $46.3 \pm 12.1$ years. Among them, 21 (45.7\%) were male, and 25 (54.3\%) were female. Most patients $(47.8 \%)$ were high school graduates. Forty-three (93.5\%) were diagnosed with schizophrenia, and three $(6.5 \%)$ with schizoaffective disorder. The mean duration of illness was $13.8 \pm 8.9$ years. Twenty-nine patients $(63.0 \%)$ initiated PP at the outpatient clinic, and the other 17 (37.0\%) initiated PP in an inpatient setting. The most common CGI-S category at the time of initiating PP was "markedly ill." Previous oral antipsychotics were converted to $\mathrm{CP}$ equivalent doses; the mean daily dose was $445.8 \pm 301 \mathrm{mg} /$ day.

\section{Number of Admissions and Bed Days}

The average number of admissions in the year before starting PP was 0.83, SD = 0.95; this decreased significantly, to $0.17, \mathrm{SD}=0.38$, the next year $(p<0.0002)$. The median number of admissions decreased from 1 to 0 after starting PP.

The mean total number of bed days in the year before starting PP was 24.85, SD = 33.77; this decreased significantly, to $8.74, \mathrm{SD}=14.98$, the year after $(p<0.006)$. The median number of total bed days decreased from 10 to 0 .

\section{Sensitivity Analyses}

We conducted post hoc sensitivity analyses by moving the mirror point from 8 days after PP initiation to the day of PP initiation (Fig. 1B) and excluded the index admission from the pre-PP and post-PP calculations (Fig. 1C) if
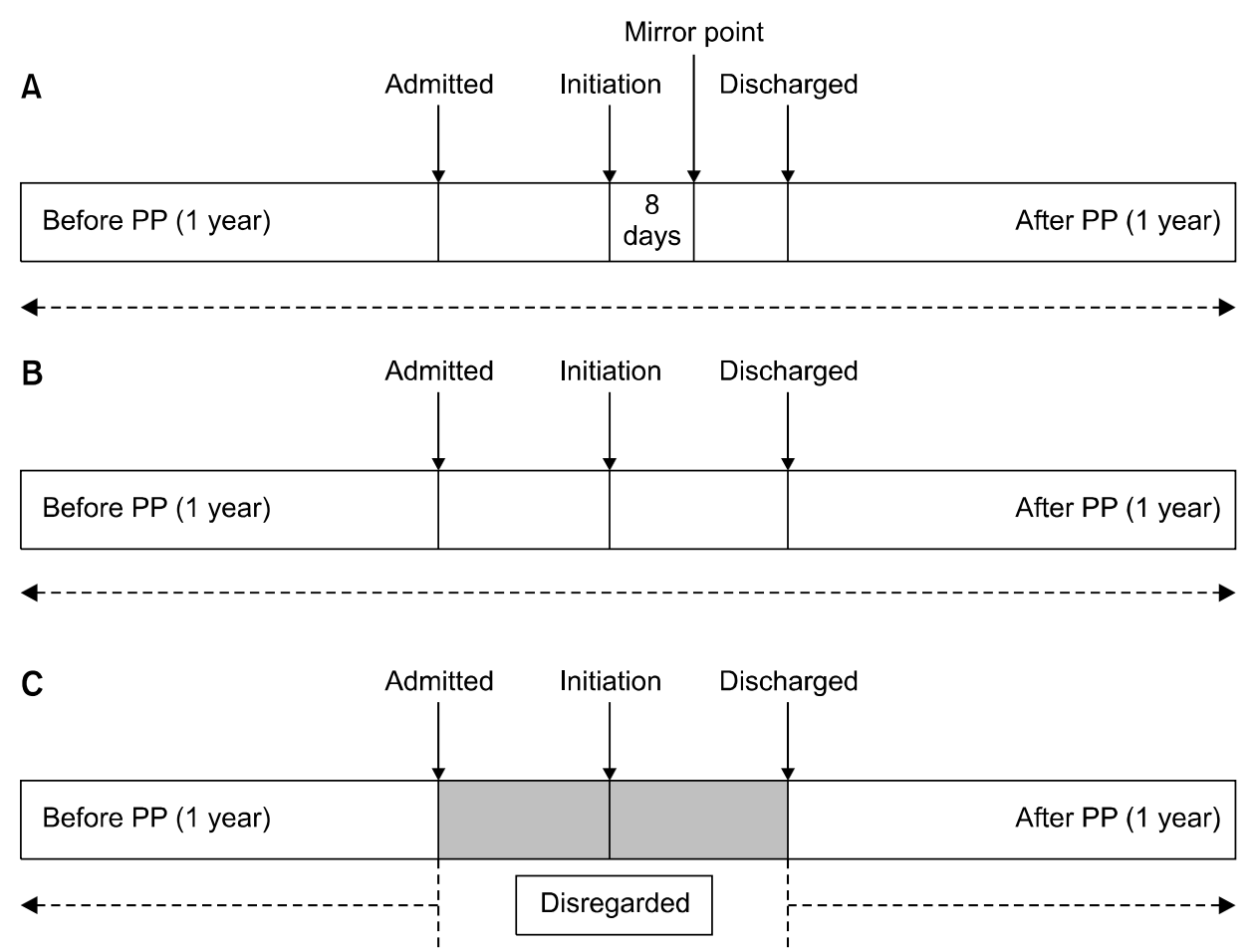

Fig. 1. Schematic representation of the mirror image method for different analyses. (A) Primary analysis (mirror point inserted at 8 days after PP initiation). (B) First sensitivity analysis (mirror point inserted at the day of PP initiation and the index admission was included for the analysis). (C) Second sensitivity analysis (mirror point inserted at the day of PP initiation and the index admission was disregarded for the analysis). PP, paliperidone palmitate. 
Table 2. Comparison of the number of admissions and the bed days before and after PP

\begin{tabular}{lccccc}
\hline \multicolumn{1}{c}{ Analysis model } & $\begin{array}{c}\text { Admissions } \\
\text { before PP }\end{array}$ & $\begin{array}{c}\text { Admissions } \\
\text { after PP }\end{array}$ & $p$ value & $\begin{array}{c}\text { Bed days } \\
\text { before PP }\end{array}$ & $\begin{array}{c}\text { Bed days } \\
\text { after PP }\end{array}$ \\
\hline Primary analysis $^{\text {a }}$ & $0.83 \pm 0.95$ & $0.17 \pm 0.38$ & $<0.0002$ & $24.85 \pm 33.77$ & $8.74 \pm 14.98$ \\
First sensitivity analysis $^{b}$ & $0.76 \pm 0.97$ & $0.17 \pm 0.38$ & $<0.001$ & $21.48 \pm 33.08$ & $9.96 \pm 17.49$ \\
Second sensitivity analysis $^{c}$ & $0.46 \pm 0.72$ & $0.17 \pm 0.38$ & $<0.032$ & $17.5 \pm 31.77$ & $4.91 \pm 12.16$ \\
\hline
\end{tabular}

Values are presented as mean \pm standard deviation.

$\mathrm{PP}$, paliperidone palmitate.

${ }^{a}$ Mirror point inserted at 8 days after PP initiation. ${ }^{b}$ Mirror point inserted at the day of PP initiation and the index admission was included for the analysis. 'Mirror point inserted at the day of PP initiation and the index admission was disregarded for the analysis.

the patient was prescribed PP in an inpatient setting. In the first analysis, with calculations based on the mirror point set as the day of initiating PP and the index admission, the mean number of pre-PP admissions was 0.76, $\mathrm{SD}=0.97$, which decreased to $0.17, \mathrm{SD}=0.38(p<0.001)$, similar to the primary analysis. The mean total number of bed days pre-PP admission was 21.48, SD = 33.08; this decreased to 9.96, $\mathrm{SD}=17.49(p<0.047)$. The benefit of the injection decreased, although it remained significant. In the second analysis, where the mirror point was set as the day of initiating PP and the index admission was disregarded in the calculation (Fig. 1C), the mean number of pre-PP admissions was $0.46, \mathrm{SD}=0.72$; this decreased to $0.17, \mathrm{SD}=0.38(p<0.032)$, similar to the first sensitivity analysis. The mean total number of bed days for pre-PP admissions was $17.5, \mathrm{SD}=31.77$, which decreased to $4.91, \mathrm{SD}=12.16(p<0.023)$. Table 2 summarizes results of our analyses.

\section{DISCUSSION}

A naturalistic 2-year mirror-image study of patients with schizophrenia revealed that after 1 year of PP injections, the number of admissions and the total number of bed days decreased considerably. Particularly, the median number of admissions fell from 1 to 0 , suggesting that at least half of the patients avoided relapse requiring a psychiatric hospital admission. In addition, the total mean number of bed days decreased over 15 days, indicating that PP may have superior efficacy compared with oral antipsychotics.

In observational mirror image studies such as this, the location of the mirror point and inclusion or exclusion of the index admission greatly influence the outcome. In cases in which the patient started PP in an outpatient set- ting, it would be reasonable to set the mirror point as the very day of PP initiation. However, if the patient started PP in the inpatient setting, it would take several days for PP to reach an effective serum concentration; thus, the efficacy of the PP injection would be underestimated if the mirror point were set as the day of PP initiation. Other studies have attempted to establish a fair comparison between the effects of PP and those of oral antipsychotics, such as by placing a mirror point on the date of initiation and excluding the number of bed days during the index admission from the analysis [24,25], placing a mirror point 2 weeks after initiation and including the number of bed days in the index admission in the analysis [26], or placing a mirror point at the date of initiation and including the number of bed days of the index admission in the analysis [27]. As mentioned earlier, in the present study, we counted the index admission for the before-PP side because the index admission was considered a failure of previous oral antipsychotics. When calculating the number of bed days for each admission, the mirror point was placed 8 days after the first PP injection because it might take 8 days to reach a therapeutic plasma concentration in most patients. If the bed days in an index admission accumulate, it would be due to a lack of efficacy of PP; hence, we did not exclude the index admission from the analysis.

In some sensitivity analyses in previous studies, the number of bed days decreased after the PP injection, but the difference was not large enough to be significant [24-28]. However, in the present study, the number of bed days decreased significantly in all settings, suggesting that the efficacy of PP is superior to that of oral antipsychotics. Although we included all consecutive patients who were prescribed two doses of the initiation regimen to minimize selection bias, 14 of 89 patients were excluded from the analysis because of incomplete medical 
records or due to follow-up loss. Patients lost to follow-up are considered noncompliant to drugs, and noncompliance increases the risk of relapse and admission [29]; this could be the reason for the superior outcome compared to previous studies. One of the most powerful strengths of LAls is their ability to enhance medication adherence, and the advantage of a mirror-image study is that the sample consists of real-world patients; thus, it would be fairer if patients lost to follow-up could be included in the analysis.

In addition, after South Korea's mental health and welfare law was revised and the new one came into effect in May 2017, psychiatric admission procedures have become complex, which could have influenced the outcome.

This study has several limitations. First, we reviewed the patients from a single medical center; thus, the sample size was modest. In addition, a 2-year follow-up period is quite short to evaluate the long-term effects of LAls. Second, we assessed the efficacy of the LAls indirectly through the number and duration of psychiatric admissions. There are various ways to evaluate therapeutic effects in patients with schizophrenia. For example, clinical scales, such as the Positive and Negative Syndrome Scale, caretaker report, or clinicians' report could help assess the therapeutic effect [30]. Third, as this study was an observational mirror-image study, no control group was used; each patient acted as his or her own control. Therefore, we cannot conclude that the efficacy of PP is greater than that of any specific oral antipsychotic. In addition, due to the nature of this observational study, we could not control bias or confounding variables, as would be possible in a randomized controlled study. To minimize selection bias, this study included every consecutive patient who was prescribed two doses of a PP initiation regimen.

As drug efficacy and safety are associated with race, ethnicity, and lifestyle variables, research needs to be conducted in many countries and in a various settings [31]. However, only a few studies have been conducted in South Korea on the effectiveness of LAIs, including PP [32-34], and no mirror-image study has ever been done. Our findings with real-world patients will help clinicians to make a drug choice for their schizophrenic patients. Further studies evaluating the effects of LAIs are needed.

\section{- Conflicts of Interest}

No potential conflict of interest relevant to this article was reported.

\section{Author Contributions}

Conceptualization: So-Young Oh, Myung Hun Jung. Data acquisition: Duk-In Jon, Hyun Ju Hong, Narei Hong, Jung-Seo Yi, Daeyoung Roh. Formal analysis: So-Young Oh. Supervision: Myung Hun Jung. Writing-original draft: So-Young Oh. Writing-review\&editing: Myung Hun Jung.

\section{ORCID}

So-Young Oh

Duk-In Jon

Hyun Ju Hong

Narei Hong

Jung-Seo Yi

Daeyoung Roh

Myung Hun Jung https://orcid.org/0000-0001-8650-6739 https://orcid.org/0000-0002-1565-7940 https://orcid.org/0000-0002-6348-9996 https://orcid.org/0000-0002-3781-9939 https://orcid.org/0000-0001-8093-6412 https://orcid.org/0000-0001-7242-9496 https://orcid.org/0000-0003-2393-3930

\section{REFERENCES}

1. Ascher-Svanum H, Faries DE, Zhu B, Ernst FR, Swartz MS, Swanson JW. Medication adherence and long-term functional outcomes in the treatment of schizophrenia in usual care. $J$ Clin Psychiatry 2006;67:453-460.

2. Miyamoto S, Duncan GE, Marx CE, Lieberman JA. Treatments for schizophrenia: a critical review of pharmacology and mechanisms of action of antipsychotic drugs. Mol Psychiatry 2005; 10:79-104.

3. Morken G, Widen JH, Grawe RW. Non-adherence to antipsychotic medication, relapse and rehospitalisation in recent-onset schizophrenia. BMC Psychiatry 2008;8:32.

4. Novick D, Haro JM, Suarez D, Perez V, Dittmann RW, Haddad PM. Predictors and clinical consequences of non-adherence with antipsychotic medication in the outpatient treatment of schizophrenia. Psychiatry Res 2010;176:109-113.

5. Barkhof E, Meijer CJ, de Sonneville LM, Linszen DH, de Haan L. Interventions to improve adherence to antipsychotic medication in patients with schizophrenia--a review of the past decade. Eur Psychiatry 2012;27:9-18.

6. Haddad PM, Brain C, Scott J. Nonadherence with antipsychotic medication in schizophrenia: challenges and management strategies. Patient Relat Outcome Meas 2014;5:43-62.

7. Park SC, Choi MY, Choi J, Park E, Tchoe HJ, Suh JK, et al. Comparative efficacy and safety of long-acting injectable and oral second-generation antipsychotics for the treatment of schizophrenia: a systematic review and meta-analysis. Clin Psychopharmacol Neurosci 2018;16:361-375.

8. Ardic UA, Küçükköse M, Inci SB, Ercan ES. Efficacy and safety profile of risperidone long-acting injection in adolescents in a real-life setting. Clin Psychopharmacol Neurosci 2018;16: 
57-61.

9. Brissos S, Veguilla MR, Taylor D, Balanzá-Martinez V. The role of long-acting injectable antipsychotics in schizophrenia: a critical appraisal. Ther Adv Psychopharmacol 2014;4: 198-219.

10. Dolder C, Nelson M, Deyo Z. Paliperidone for schizophrenia. Am J Health Syst Pharm 2008;65:403-413.

11. Jarema M, Bieńkowski P, Heitzman J, Parnowski T, Rybakowski J. Paliperidone palmitate: effectiveness, safety, and the use for treatment of schizophrenia. Psychiatr Pol 2017;51:7-21.

12. Gopal S, Hough DW, Xu H, Lull JM, Gassmann-Mayer C, Remmerie BM, et al. Efficacy and safety of paliperidone palmitate in adult patients with acutely symptomatic schizophrenia: a randomized, double-blind, placebo-controlled, dose-response study. Int Clin Psychopharmacol 2010;25: 247-256.

13. Hough D, Gopal S, Vijapurkar U, Lim P, Morozova M, Eerdekens M. Paliperidone palmitate maintenance treatment in delaying the time-to-relapse in patients with schizophrenia: a randomized, double-blind, placebo-controlled study. Schizophr Res 2010;116:107-117.

14. Kramer M, Litman R, Hough D, Lane R, Lim P, Liu Y, et al. Paliperidone palmitate, a potential long-acting treatment for patients with schizophrenia. Results of a randomized, double-blind, placebo-controlled efficacy and safety study. Int J Neuropsychopharmacol 2010;13:635-647.

15. Pandina GJ, Lindenmayer JP, Lull J, Lim P, Gopal S, Herben V, et al. A randomized, placebo-controlled study to assess the efficacy and safety of 3 doses of paliperidone palmitate in adults with acutely exacerbated schizophrenia. J Clin Psychopharmacol 2010:30:235-244.

16. Kishimoto T, Nitta M, Borenstein M, Kane JM, Correll CU. Long-acting injectable versus oral antipsychotics in schizophrenia: a systematic review and meta-analysis of mirror-image studies. J Clin Psychiatry 2013;74:957-965.

17. Kishimoto T, Robenzadeh A, Leucht C, Leucht S, Watanabe K, Mimura M, et al. Long-acting injectable vs oral antipsychotics for relapse prevention in schizophrenia: a meta-analysis of randomized trials. Schizophr Bull 2014;40:192-213.

18. Haddad PM, Kishimoto T, Correll CU, Kane JM. Ambiguous findings concerning potential advantages of depot antipsychotics: in search of clinical relevance. Curr Opin Psychiatry 2015;28:216-221.

19. Kane JM, Kishimoto T, Correll CU. Non-adherence to medication in patients with psychotic disorders: epidemiology, contributing factors and management strategies. World Psychiatry 2013;12:216-226.

20. American Psychiatric Association. Diagnostic and statistical manual of mental disorders. 5th ed. Arlington:American
Psychiatric Association;2013.

21. Guy W. ECDEU assessment manual for psychopharmacology. Rockvile:US Department of Health, Education, and Welfare; 1976. p.534-537.

22. Woods SW. Chlorpromazine equivalent doses for the newer atypical antipsychotics. J Clin Psychiatry 2003;64:663-667.

23. Gopal S, Gassmann-Mayer C, Palumbo J, Samtani MN, Shiwach R, Alphs L. Practical guidance for dosing and switching paliperidone palmitate treatment in patients with schizophrenia. Curr Med Res Opin 2010;26:377-387.

24. Taylor D, Olofinjana O. Long-acting paliperidone palmitate interim results of an observational study of its effect on hospitalization. Int Clin Psychopharmacol 2014;29:229-234.

25. Taylor DM, Sparshatt A, O'Hagan M, Dzahini O. Effect of paliperidone palmitate on hospitalisation in a naturalistic cohort - a four-year mirror image study. Eur Psychiatry 2016;37:43-48.

26. Bressington D, Stock J, Hulbert S, MacInnes D. A retrospective observational study of the effectiveness of paliperidone palmitate on acute inpatient hospitalization rates. Int Clin Psychopharmacol 2015;30:230-236.

27. Vincent PD, Demers MF, Doyon-Kemp V, Duchesneau J, Halme A, Masson V. One year mirror-image study using paliperidone palmitate for relapse prevention of schizophrenia in four university hospitals in Canada. Schizophr Res 2017; 185:96-100.

28. Nikolić N, Page N, Akram A, Khan M. The impact of paliperidone palmitate long-acting injection on hospital admissions in a mental health setting. Int Clin Psychopharmacol 2017;32. 95-102.

29. Ayuso-Gutiérrez JL, del Río Vega JM. Factors influencing relapse in the long-term course of schizophrenia. Schizophr Res 1997;28:199-206.

30. Kay SR, Fiszbein A, Opler LA. The positive and negative syndrome scale (PANSS) for schizophrenia. Schizophr Bull 1987; 13:261-276.

31. Cutler A, Ball S, Stahl SM. Dosing atypical antipsychotics. CNS Spectr 2008;13(5 Supp/ 9):1-16.

32. Kang HK, Hahm W, Shon IK, Paik IH. Safety and effectiveness of long acting injectable antipsychotic paliperidone palmitate treatment in schizophrenics: a 24-week open-label study. Korean J Biol Psychiatry 2013;20:111-117.

33. Kim BR, Lee TJ, Woo JM, Park JI, Kwon JS. Cost-utility analysis of paliperidone palmitate long acting injection (PLAl) versus oral atypical antipsychotics in non-adherent schizophrenia patients in South Korea. Korean J Psychopharmacol 2012;23: $17-27$.

34. Kim H, Lee J, Kim C, Joo Y. The drug adherence and treatment effect of the paliperidone long acting injection. I Korean Neuropsychiatr Assoc 2015;54:69-75. 